\title{
So gelingt der Schulterblick
}

\author{
YOGA bei Gesundheitsproblemen — Beim „Schulterblick“ im Auto ist die eingeschränkte \\ Beweglichkeit im Bereich der Brust- und Halswirbelsäule deutlich spürbar. Diese Einschrän- \\ kung lässt sich durch Rotationsübungen gut beseitigen. Die Drehbewegungen vermitteln auch \\ ein Gespür für die unterschiedliche Beweglichkeit der beiden Körperhälften.
}

\section{Schnelle Wirkung}

Der Hand nachschauen: Diese Übung lässt sich im Stehen und im Sitzen durchführen. Im Sitzen eine aufrechte Haltung einnehmen und die Hände mit den Innenflächen nach unten auf den Oberschenkeln ablegen. In eine aufrechte Standposition kommen und beide Hände auf der Bauchdecke ruhen lassen. In der Ausgangsposition zuerst auf die rechte Hand schauen und der Hand später, während der Übung, hinterher schauen. Auf diese Weise erfolgt eine sanfte Rotation der Wirbelsäule verbunden mit einem Nicken des Kopfes. Aufmerksamkeit und Konzentration werden gefördert. Einatmend die rechte Hand heben und aus dem Ellenbogengelenk heraus nach außen drehen bis Hand und Unterarm im rechten Winkel seitlich vom Körper abstehen. Ausatmend die rechte Hand anheben und auf der linken Schulter ablegen. Einatmend die rechte Hand wieder aus dem Ellenbogengelenk heraus seitlich nach außen drehen. Ausatmend die Hand wieder in die Ausgangsposition bringen. Nun auf die linke Hand schauen und die Übung wiederholen.

\section{Anhaltende Wirkung}

Der Drehsitz: Im Drehsitz wird vor allem die hintere Hüftmuskulatur gedehnt. Damit die Wirbel gedreht werden können, müssen die Wirbelgelenke frei beweglich sein. Darum sollte jeder Drehung eine maximale Streckung der Wirbelsäule voraus gehen. Bei akuten Schmerzen im Bauch und in der Wirbelsäule sollte diese Übung nicht gemacht werden. Für Schwangere sind Drehbewegungen, die den Druck auf den Bauchraum erhöhen, nicht geeignet.

Bequem auf den Boden setzen und das Gewicht gleichmäßig auf beide Sitzhöcker verteilen. Die Beine strecken, die Wirbelsäule aufrichten und mit den Händen die aufrechte Körperhaltung unterstützen (Foto 1). Diese Aufrichtung beibehalten, das linke Bein beugen und den linken Fuß neben die Außenseite des gestreckten rechten Beins in Kniehöhe absetzen (Foto 2). Die rechte Hand umfasst das gebeugte linke Knie, die linke Hand bleibt als Rückenstütze.

Durch die Nase einatmen, und dabei den Oberkörper zum gebeugten linken Knie heranziehen, die Wirbelsäule auf- richten. Diese Aufrichtung bei der Ausatmung beibehalten.

Mit der nächsten Einatmung weiter aufrichten, den rechten Ellenbogen um das linke Knie schließen und mit der nächsten Ausatmung den Oberkörper zur Seite der aufgestellten Hand drehen. Mit der nächsten Einatmung nochmals die Wirbelsäule strecken, den Oberkörper zum gebeugten Knie ziehen und mit der nächsten Ausatmung den Oberkörper noch etwas weiter drehen.Wenn die maximale Position erreicht ist, diese einige Atemzüge lang halten (Foto 3). Ausatmend wieder zurück in die Ausgangsposition drehen und beide Körperhälften miteinander vergleichen. Unterschiede in der Wahrnehmung der beiden Beine, der beiden Beckenseiten, der beiden Schultern sowie der Gesichtshälften wahrnehmen. Danach die Übung zur anderen Seite wiederholen.

\footnotetext{
- Prof. Dr. Ingrid Kollak

- Alice-Salomon Fachhochschule Berlin Yoga-Lehrerin BDY/EYU

_ Email: kollak@asfh-berlin.de (Betreff: Yoga bei ...)
}

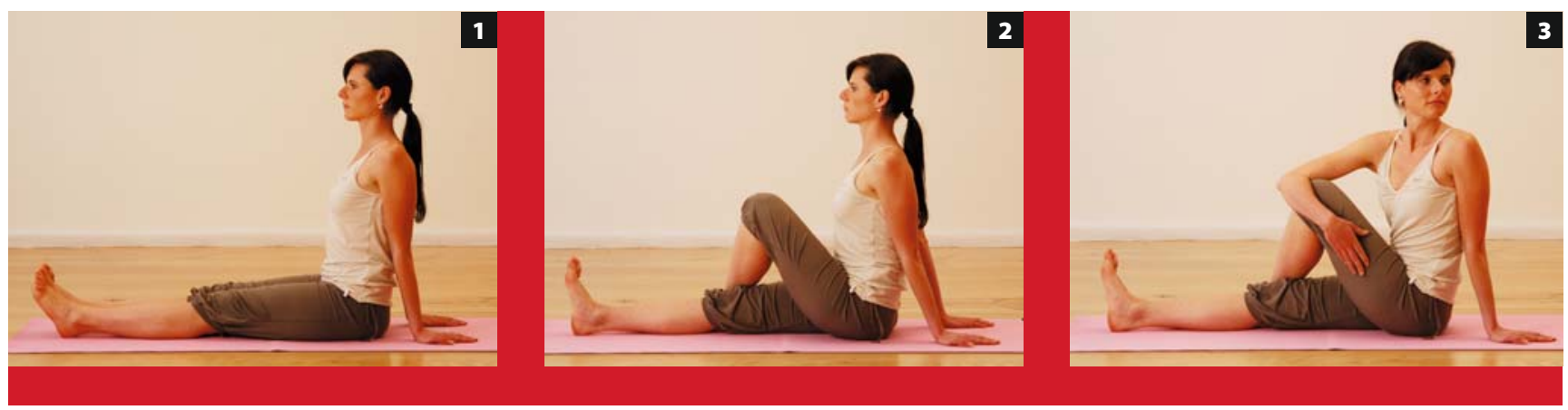

